\title{
Prevalence and Burden of Physical Problems in Female College Basketball Athletes: A I35-Day Prospective Cohort Study
}

\author{
Yasuharu Nagano (D) \\ Yui Shimada ${ }^{2}$ \\ Naoki Sasaki ${ }^{1}$ \\ Masaki Shibata' \\ 'Faculty of Physical Education, Japan \\ Women's College of Physical Education, \\ Tokyo, Japan; ${ }^{2}$ Faculty of Health Sciences, \\ Tokyo Ariake University of Medical and \\ Health Sciences, Tokyo, Japan
}

Introduction: The purpose of this prospective cohort study was to investigate the prevalence and burden of "any physical complaint" in college female basketball athletes using a daily questionnaire.

Methods: Fifty-four female college basketball players were recruited and followed up for 135 days using the Oslo Sports Trauma Research Centre questionnaire.

Results: The questionnaire response rate was $96.4 \%$ (95\% confidence interval: $95.7-97.1)$. The average daily prevalence of any problem was $44.4 \%$, whereas that of substantial problems was $16.0 \%$. The anatomical areas found to be most frequently affected by physical problems were the ankle (average daily prevalence: $14.5 \%, 95 \%$ confidence interval: $13.4-$ 15.7), lower back $(14.4 \%, 95 \%$ confidence interval: $13.7-15.2)$, and knee $(9.6 \%, 95 \%$ confidence interval: $9.0-10.2$ ). The cumulative severity score, calculated by summing severity scores and dividing by number of respondents, showed that ankle, knee, and lower back problems exhibited greater relative burden.

Discussion: Injuries common in basketball athletes, such as ankle sprain, anterior cruciate ligament injury, overuse knee pain, and low-back pain, are reflected in the present data.

Keywords: epidemiology, sports injuries, overuse injuries, ankle, knee

\section{Introduction}

In ball games, such as basketball, athletes perform intensive repeated movements characterized by acceleration, deceleration, change of direction, stop, jump, and landing, ${ }^{1,2}$ all of which may predispose them to lower limb injuries, such as anterior cruciate ligament (ACL) injury ${ }^{3,4}$ and ankle sprain. ${ }^{5}$ Basketball players often experience severe injuries, especially in their ankle and knee. ${ }^{6}$ ACL injury $^{3,4}$ and ankle sprain $^{5}$ are representative examples of these injuries. Ankle sprain requires considerable healing time before the athletes can return to play. ${ }^{5}$ ACL injury reduces player performance and that results in a reduced probability of returning to preinjury levels. ${ }^{7}$ In addition, sequelae of acute injuries often lead to another overuse injury. ${ }^{8}$ Overuse injuries of the knee are also relatively common in basketball. ${ }^{9}$ As overuse injuries do not often lead to time-loss injury, surveys using time-loss injury cannot accurately detect the status of injury and the condition of athletes. ${ }^{10}$ Moreover, overuse often leads to substantial consequences that decrease the performance and volume of play of athletes, even if it does not lead to time-loss injury. ${ }^{11}$ Therefore, to properly understand the condition of
Correspondence: Yasuharu Nagano Faculty of Physical Education, Japan Women's College of Physical Education, 8-19-I, Kitakarasuyama, Setagaya, Tokyo, 157-8565, Japan

Tel $+8 \mathrm{I}-3-3300-5437$

Fax +8I-3-3300-5437

Email nagano.yasuharu@jwcpe.ac.jp 
athletes, including acute and overuse injuries, monitoring should be performed using the definition of "any physical complaint". ${ }^{10}$

When epidemiological studies are interpreted, different injury definitions are important. A novel injury surveillance questionnaire was developed to register any physical complaint, which is known as the Oslo Sports Trauma Research Centre (OSTRC) overuse injury questionnaire ${ }^{12}$ and the OSTRC questionnaire on health problems. ${ }^{13}$ These questionnaires collect data from athletes regarding pain, limited participation in training and competition, and reduced training volume and performance capacity in sports. These questionnaires have reported the prevalence of overuse injury in cross-country skiing, floorball, handball, road cycling, and volleyball, ${ }^{11,12}$ overuse injury among youth football players, ${ }^{14}$ health problems in Olympic and Paralympic athletes, ${ }^{13}$ and health problems in youth elite sports athletes. ${ }^{15}$ The questionnaires were also translated into Danish, ${ }^{16}$ Swedish, ${ }^{17}$ German, ${ }^{18}$ and Japanese. ${ }^{19}$ However, no data specific to basketball players were reported. In addition, because these questionnaires are usually registered weekly, they are not suited for monitoring the daily condition of athletes. Coaches or trainers of the team need daily data to understand the conditions of the athletes and determine subsequent training or rehabilitation programs.

Therefore, the purpose of this prospective cohort study was to investigate the prevalence and burden of "any physical complaint" in college female basketball athletes using a daily questionnaire. In these procedures, we could detect daily changes in the conditions of the athletes.

\section{Materials and Methods}

This prospective study was approved by the ethical review board of Japan Women's College of Physical Education and complied with the ethical principles of the Declaration of Helsinki. All athletes provided written informed consent prior to participating in the study.

\section{Study Group}

In total, 54 female college basketball players (age $19.0 \pm$ 2.8 years; body mass $60.1 \pm 6.0 \mathrm{~kg}$; height $165.0 \pm 6.0 \mathrm{~cm}$; years of experience $10.2 \pm 2.1$ years [mean $\pm \mathrm{SD}]$ ) were recruited from a college in the province of Tokyo, Japan. The positions played by the participants were guard $(\mathrm{n}=$ 11), shooting guard $(\mathrm{n}=4)$, forward $(\mathrm{n}=30)$, forward/ center $(\mathrm{n}=1)$, and center $(\mathrm{n}=8)$. They were recruited from one college and were divided to three teams for practice and game. When we set the expected proportion of prevalence as 0.5 , the total width of the confidence interval as 0.3 , and the level of confidence as $95 \%$, the required number of participants was $43 .^{20}$ The Japanese version of the modified OSTRC questionnaire ${ }^{19}$ was distributed daily to all athletes electronically for 135 days (19 weeks) using the conditioning reporting application ONE TAP SPORTS (Euphoria Co., Ltd., Japan). This period was set from the beginning to end of the autumn season. In the present study, we added questions that asked about the anatomical areas the athletes complained about the most as well as questions regarding other anatomical areas of concern. ${ }^{19}$ Also, we changed the target of the questionnaire from the "past week" to the "past day" and administered the questionnaire every day. Participants were requested to respond to the questionnaire at a set time every day, and these were checked by the coaches and trainers. If responses had points of uncertainly, a trainer confirmed these responses directly with the player. After the study period, a researcher extracted and interpreted the data.

\section{Prevalence Measures}

The prevalence of problems was calculated for all problems as well as for each anatomical area during each day of the study period by dividing the number of athletes who reported any complaints by the number of respondents to the questionnaire. ${ }^{11}$ For each anatomical area, the numerator in the prevalence calculation included the number of individuals who selected each anatomical area as the chief complaint area and those who reported it as an additional complaint. Also, we calculated the average prevalence of substantial problems, defined as problems that led to moderate or severe reduction in training volume or performance or complete time-loss from sport. ${ }^{11,19}$ Every time an athlete responded to the questionnaire, we calculated a severity score (ranging from 0 to 100) for the most complained anatomical area, based on the participants' responses to the four key questions. ${ }^{12}$ In addition, the total number and new onset of the most complained problem in each anatomical area were calculated to examine the duration of the new problem. New onset was defined as a problem that had not been reported during the previous 7 days.

\section{Statistics}

The response rate and prevalence were expressed as mean values and $95 \%$ confidence intervals (CIs). Weekly coefficients of variation of prevalence were also calculated and 
averaged throughout the study period (19 weeks) with 95\% CI. Injury burden is defined as "the cross product of severity and incidence"; ${ }^{21}$ therefore, in the present study, we have defined the it as follows: for each anatomical region, the cumulative severity score was calculated by summing the severity scores for all players over the 135 days and dividing by the mean number of weekly respondents ${ }^{14}$ to compare the relative injury burden between anatomical areas.

\section{Results}

\section{Response Rate}

In total, 7027 questionnaires were completed. The response rate to the 135 daily questionnaires was $96.4 \%$ (95\% CI: 95.7-97.1). The highest response rate was 100\%, and the lowest rate was $87.0 \%$. There were no dropouts from this study.

\section{Prevalence of Problems}

Table 1 shows the average prevalence of all problems and that of substantial problems for each anatomical area. The most frequently reported problematic areas were the ankle, lower back, and knee. Figure 1 illustrates the prevalence of all problems and substantial problems during the 135 days of the study period. The average weekly coefficient of variation of prevalence was 0.10 (95\% CI: $0.08-0.12$ ). Table 2 shows the total number and new onset of the most complained problem in each anatomical area. The

Table I Average Prevalence of All Problems and of Substantial Problems

\begin{tabular}{|l|l|l|l|l|}
\hline & \multicolumn{2}{|l|}{ All Problems } & \multicolumn{2}{l|}{$\begin{array}{l}\text { Substantial } \\
\text { Problems }\end{array}$} \\
\hline Ankle & $14.5 \%$ & $(13.4-15.7)$ & $4.0 \%$ & $(3.6-4.5)$ \\
Lower back & $14.4 \%$ & $(13.7-15.2)$ & $4.0 \%$ & $(3.6-4.4)$ \\
Knee & $9.6 \%$ & $(9.0-10.2)$ & $5.2 \%$ & $(4.8-5.7)$ \\
Foot & $8.4 \%$ & $(7.7-9.1)$ & $0.4 \%$ & $(0.2-0.6)$ \\
Shank & $5.1 \%$ & $(4.3-5.9)$ & $0.6 \%$ & $(0.4-0.9)$ \\
Hip/thigh & $2.5 \%$ & $(1.7-3.3)$ & $0.3 \%$ & $(0.1-0.5)$ \\
Wrist/forearm & $2.2 \%$ & $(1.7-2.7)$ & $0.2 \%$ & $(0.0-0.4)$ \\
Finger & $1.1 \%$ & $(0.8-1.5)$ & $0.0 \%$ & $(0.0-0.1)$ \\
Internal medical & $1.1 \%$ & $(0.7-1.5)$ & $0.3 \%$ & $(0.1-0.5)$ \\
problem & & & & \\
Elbow/upper arm & $1.0 \%$ & $(0.7-1.3)$ & $0.0 \%$ & $(0.0-0.1)$ \\
Shoulder & $0.9 \%$ & $(0.5-1.3)$ & $0.1 \%$ & $(0.0-0.3)$ \\
Pelvis/glute & $0.7 \%$ & $(0.3-1.0)$ & $0.0 \%$ & $(0.0-0.0)$ \\
Other & $1.2 \%$ & $(0.8-1.5)$ & $0.2 \%$ & $(0.0-0.4)$ \\
Total & $44.4 \%$ & $(42.7-46.2)$ & $16.0 \%$ & $(15.2-16.8)$ \\
\hline
\end{tabular}

Note: Data are presented as percentages with 95 confidence intervals.

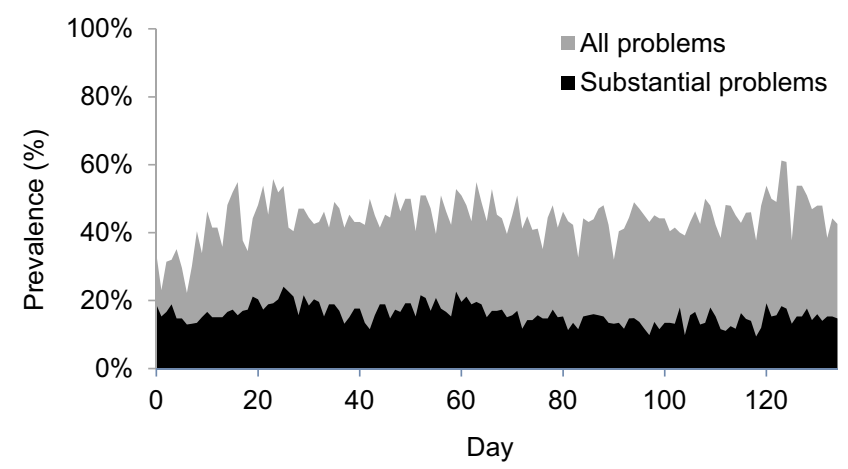

Figure I Prevalence of all and substantial problems. The gray area indicates the prevalence of all problems, and the black area indicates the prevalence of substantial problems.

total number / new onset problem was highest in the knee, followed by the lower back, shank, ankle, and foot.

\section{Severity Score}

Figure 2 displays the adjusted cumulative severity score, and a greatest relative burden was seen for ankle, knee, and lower back problems. Subsequently, the foot and shank had large burdens. These anatomical areas that showed greater relative burden were the same for the prevalence of problems.

\section{Discussion}

The purpose of this prospective cohort study was to investigate the prevalence and burden of "any physical complaint" in college female basketball athletes using a daily

Table 2 Total Number and New Onset of Most Complained Problem in Each Anatomical Area

\begin{tabular}{|l|c|c|c|}
\hline & $\begin{array}{c}\text { Total } \\
\text { (Cases) }\end{array}$ & $\begin{array}{c}\text { New Onset } \\
\text { (Cases) }\end{array}$ & $\begin{array}{c}\text { Total/New } \\
\text { Onset }\end{array}$ \\
\hline Ankle & 834 & 42 & 19.9 \\
Kower back & 799 & 35 & 22.8 \\
Snee & 667 & 24 & 27.8 \\
Foot & 299 & 14 & 21.4 \\
Hip/thigh & 297 & 21 & 14.1 \\
Wrist/forearm & 111 & 24 & 4.6 \\
Shoulder & 88 & 9 & 9.8 \\
Finger & 55 & 9 & 6.1 \\
Internal medical & 30 & 6 & 6.7 \\
problem & 37 & 10 & 3.7 \\
Elbow/upper arm & 18 & 7 & 6.7 \\
Pelvis/glute & 6 & 9 & 15.7 \\
Other & 60 & 211 & 6.0 \\
Total & 3311 & & \\
\hline
\end{tabular}




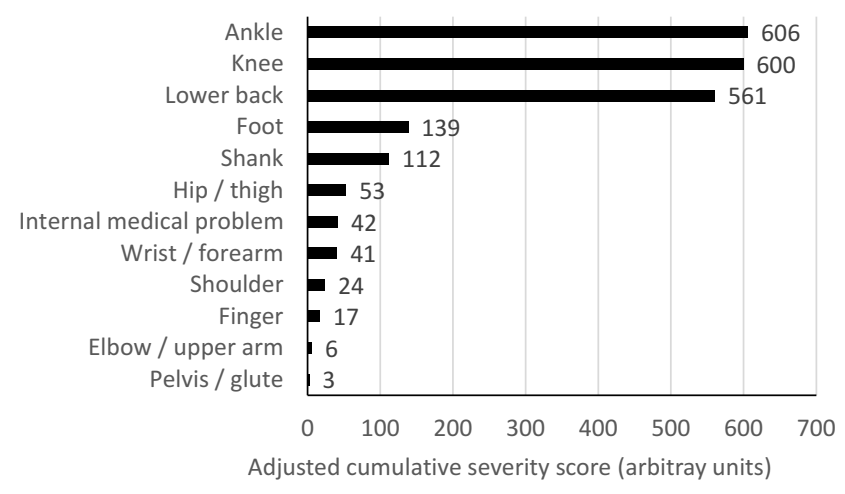

Figure 2 Relative burden of problems, shown as the adjusted cumulative score. The cumulative severity score was calculated by summing the severity scores for all players over the 135 days and dividing by the mean number of weekly respondents.

questionnaire. Using the OSTRC questionnaire, we were able to grasp the precise conditions of the any physical complaints definition, including sequelae after acute and overuse injury. Furthermore, as the questionnaire was conducted daily and responses were available to coaches and trainers immediately, the condition of the players could be checked daily to identify any physical problems early and control training details and volume. Conversely, weekly questionnaires would cause a delay for on-time coaches and trainers to determine precise conditions because the prevalence rate was $10 \%$ in a week, as demonstrated by the weekly coefficient of variation. The response rate in the present study was high throughout the research period, although we assigned a daily response. These trends were consistent with those reported in previous studies using the OSTRC overuse questionnaire ${ }^{11}$ and higher than that using OSTRC health problem questionnaire. ${ }^{13,15}$ Completing the questionnaire as a daily habit would not result in reduced response rates, even if the study period was longer. Therefore, the results of our research on female basketball athletes demonstrated that we could successfully capture daily data on all physical complaints, with a high response rate.

The findings of this study demonstrated that the prevalence of any problems varied by days. The average daily prevalence of any problems was $44.4 \%$, whereas that of substantial problems was $16.0 \%$. Also, these results are in agreement with the findings of previous studies using the OSTRC health problem questionnaire in Olympic and Paralympic athletes (36\% and $15 \%$ for all and substantial problems, respectively $)^{13}$ and in youth elite sports athletes ( $45 \%$ and $26 \%$ for all and substantial problems, respectively in team sports athletes). ${ }^{15}$ Although those studies did not include basketball athletes ${ }^{13}$ or included only a few basketball athletes, ${ }^{15}$ participants in the present study showed a similar trend for prevalence of all and substantial problems. Although no existing data exist reporting the prevalence of any physical problems in basketball athletes using the OSTRC questionnaire, data of the present could grasp the precise conditions that may be missed using only "time-loss injury" or "medical attention" definitions.

Among the anatomical areas, problems occurred frequently in the ankle and lower back, followed by the knee. More substantial problems occurred in the knee area than in other anatomical area. As a result, the adjusted cumulative score was comparable in the ankle, lower back, and knee. Ankle sprain was the most common ankle injury in basketball players, ${ }^{4,21}$ and the number of recurrent of ankle sprains was high. ${ }^{5}$ Among lower back problems, overuse low-back pain is common in basketball players. ${ }^{21-23}$ The prevalence of lower back problems in the players in the present study was comparable with that reported previously in the volleyball and handball players, ${ }^{11}$ whereas the prevalence of substantial lower back problems was higher: $4 \%$ in the present study and $1-2 \%$ in the previous study. ${ }^{11}$ Coaches and trainers should understand these conditions to prevent worsening of low-back pain. In the knee, both acute and overuse problems occur often. ${ }^{4,6,21,22}$ One of the common acute knee problems is the ACL injury. ${ }^{4}$ After ACL injuries, returning to play for basketball players may take up to 10 months, and sports performance may be affected for longer periods. ${ }^{24}$ In addition, overuse knee problems are believed to be caused by anterior knee pain, ${ }^{22}$ patellofemoral pain, ${ }^{21}$ and patellar tendinopathy. ${ }^{4}$

The results of the present study demonstrated a greater prevalence of substantial problems and a comparable cumulative score in ankle and lower back and reflected the greater impact of knee problems, which worsened the conditions of basketball athletes. As a whole, the present study could help improve the understanding of physical complaints and conditions of basketball athletes.

The current study exhibits some limitations. First, the research period was during only part of a year with limited participation by three teams. The tendency for injury in other populations or during other periods of the year might be different. Future studies should be conducted in a large population with the duration of at least 1 year. Second, we did not distinguish between acute and overuse problems. However, athletes often continue their training and game participation after minor acute injury, which can become chronic problems in some cases. Moreover, athletes often experience acutely aggravated overuse problems. Therefore, we 
performed a comprehensive registration of the problems. Third, diagnoses for each problem were not found because the questionnaire was self-reported. However, the advantage of the present study is that we could detect any physical complaint. Finally, the exact duration of each problem was not recorded. As the results of the present study were independent day by day, a new system to identify the duration of each problem is necessary.

\section{Funding}

There is no funding to report.

\section{Disclosure}

The authors declare that no potential conflicts of interest exist.

\section{References}

1. Koyama T, Rikukawa A, Nagano Y, Sasaki S, Ichikawa H, Hirose N. Acceleration profile of high-intensity movements in basketball games. $J$ Strength Cond Res. 2020. doi:10.1519/JSC.0000000000003 699

2. Stojanovic E, Stojiljkovic N, Scanlan AT, Dalbo VJ, Berkelmans DM, Milanovic Z. The activity demands and physiological responses encountered during basketball match-play: a systematic review. Sports Med. 2018;48(1):111-135. doi:10.1007/s40279-017-0794-z

3. Krosshaug T, Nakamae A, Boden BP, et al. Mechanisms of anterior cruciate ligament injury in basketball: video analysis of 39 cases. $\mathrm{Am}$ J Sports Med. 2007;35(3):359-367. doi:10.1177/0363546506293899

4. McCarthy MM, Voos JE, Nguyen JT, Callahan L, Hannafin JA. Injury profile in elite female basketball athletes at the Women's National Basketball Association combine. Am J Sports Med. 2013;41 (3):645-651. doi:10.1177/0363546512474223

5. Pasanen K, Ekola T, Vasankari T, et al. High ankle injury rate in adolescent basketball: a 3-Year Prospective Follow-Up Study. Scand J Med Sci Sports. 2017;27(6):643-649. doi:10.1111/sms.12818

6. Clifton DR, Hertel J, Onate JA, et al. The First decade of web-based sports injury surveillance: descriptive epidemiology of injuries in US high school girls' basketball (2005-2006 through 2013-2014) and national collegiate athletic association women's basketball (2004-2005 through 2013-2014). $J$ Athl Train. 2018;53(11):1037-1048. doi:10.4085/1062-6050-150-17

7. Ardern CL, Taylor NF, Feller JA, Whitehead TS, Webster KE. Sports participation 2 years after anterior cruciate ligament reconstruction in athletes who had not returned to sport at 1 year: a prospective follow-up of physical function and psychological factors in 122 athletes. Am J Sports Med. 2015;43(4):848-856. doi:10.1177/ 0363546514563282

8. Backman LJ, Danielson P. Low range of ankle dorsiflexion predisposes for patellar tendinopathy in junior elite basketball players: a 1-Year Prospective Study. Am J Sports Med. 2011;39(12):2626-2633. doi:10.1177/0363546511420552

9. Leppanen M, Pasanen K, Kannus P, et al. Epidemiology of overuse injuries in youth team sports: a 3-Year Prospective Study. Int J Sports Med. 2017;38(11):847-856. doi:10.1055/s-0043-114864
10. Bahr R. No injuries, but plenty of pain? On the methodology for recording overuse symptoms in sports. Br J Sports Med. 2009;43 (13):966-972. doi:10.1136/bjsm.2009.066936

11. Clarsen B, Bahr R, Heymans MW, et al. The prevalence and impact of overuse injuries in five Norwegian sports: application of a new surveillance method. Scand J Med Sci Sports. 2015;25(3):323-330. doi: $10.1111 /$ sms. 12223

12. Clarsen B, Myklebust G, Bahr R. Development and validation of a new method for the registration of overuse injuries in sports injury epidemiology: the Oslo Sports Trauma Research Centre (OSTRC) overuse injury questionnaire. Br J Sports Med. 2013;47(8):495-502. doi:10.1136/bjsports-2012-091524

13. Clarsen B, Ronsen O, Myklebust G, Florenes TW, Bahr R. The Oslo Sports Trauma Research Center questionnaire on health problems: a new approach to prospective monitoring of illness and injury in elite athletes. Br J Sports Med. 2014;48(9):754-760. doi:10.1136/ bjsports-2012-092087

14. Leppanen M, Pasanen K, Clarsen B, et al. Overuse injuries are prevalent in children's competitive football: a prospective study using the OSTRC overuse injury questionnaire. Br J Sports Med. 2019;53(3):165-171. doi:10.1136/bjsports-2018-099218

15. Moseid CH, Myklebust G, Fagerland MW, Clarsen B, Bahr R. The prevalence and severity of health problems in youth elite sports: a 6-month prospective cohort study of 320 athletes. Scand J Med Sci Sports. 2018;28(4):1412-1423. doi:10.1111/sms.13047

16. Jorgensen JE, Rathleff CR, Rathleff MS, Andreasen J. Danish translation and validation of the Oslo Sports Trauma Research Centre questionnaires on overuse injuries and health problems. Scand J Med Sci Sports. 2016;26(12):1391-1397. doi:10.1111/sms. 12590

17. Ekman E, Frohm A, Ek P, Hagberg J, Wiren C, Heijne A. Swedish translation and validation of a web-based questionnaire for registration of overuse problems. Scand J Med Sci Sports. 2015;25 (1):104-109. doi:10.1111/sms.12157

18. Hirschmuller A, Steffen K, Fassbender K, et al. German translation and content validation of the OSTRC Questionnaire on overuse injuries and health problems. Br J Sports Med. 2017;51(4):260-263. doi:10.1136/bjsports-2016-096669

19. Nagano Y, Kobayashi-Yamakawa K, Higashihara A, Yako-Suketomo H. Japanese translation and modification of the Oslo Sports Trauma Research Centre overuse injury questionnaire to evaluate overuse injuries in female college swimmers. PLoS One. 2019;14(4): e0215352. doi:10.1371/journal.pone.0215352

20. Hulley SB, Cummings SR, Browner WS, Grady DG, Newman TB. Designing Clinical Research. 4th ed. Philadelphia: Lippincott Williams \& Wilkins; 2013.

21. Drakos MC, Domb B, Starkey C, Callahan L, Allen AA. Injury in the national basketball association: a 17-year overview. Sports Health. 2010;2(4):284-290. doi:10.1177/1941738109357303

22. Cumps E, Verhagen E, Meeusen R. Prospective epidemiological study of basketball injuries during one competitive season: ankle sprains and overuse knee injuries. J Sports Sci Med. 2007;6 (2):204-211.

23. Pasanen K, Rossi M, Parkkari J, et al. Low back pain in young basketball and floorball players. Clin J Sport Med. 2016;26 (5):376-380. doi:10.1097/JSM.0000000000000263

24. Nwachukwu BU, Anthony SG, Lin KM, Wang T, Altchek DW, Allen AA. Return to play and performance after anterior cruciate ligament reconstruction in the National Basketball Association: surgeon case series and literature review. Phys Sportsmed. 2017;45 (3):303-308. doi:10.1080/00913847.2017.1325313 


\section{Publish your work in this journal}

Open Access Journal of Sports Medicine is an international, peerreviewed, open access journal publishing original research, reports, reviews and commentaries on all areas of sports medicine. The

Submit your manuscript here: http://www.dovepress.com/open-access-journal-of-sports-medicine-journal manuscript management system is completely online and includes a very quick and fair peer-review system. Visit http://www.dovepress. com/testimonials.php to read real quotes from published authors. 